\title{
Effects of surgical masks on droplet dispersion under various oxygen delivery modalities
}

\author{
Takahiro Takazono ${ }^{1,2^{*}+} @$ , Kazuko Yamamoto ${ }^{1,3 \dagger}$, Ryuta Okamoto ${ }^{4}$, Shimpei Morimoto ${ }^{5,6}$, Koichi Izumikawa 2,3 \\ and Hiroshi Mukae ${ }^{1}$
}

\section{Dear editor,}

Aerosol dispersion under oxygen delivery modalities, including the high-flow nasal cannula (HFNC), is a critical concern for healthcare workers who have treated acute hypoxemic respiratory failure during the coronavirus disease (COVID-19) pandemic. Whether HFNC increases the aerosol dispersion is still controversial [13]. This study aimed to visualize and quantify dispersion particles under various oxygen delivery modalities and examine the protective effect of surgical masks on particle dispersion.

Three and five healthy men were voluntarily enrolled for video recording and quantification of particles, respectively. In the visualization experiment, three conditions, including room air, nasal canula at $5 \mathrm{~L} / \mathrm{min}$ (nonhumidified, Nakamura Medical Industry Co., Ltd.), and HFNC at $60 \mathrm{~L} / \mathrm{min}$ (humidified, AIRVO2/Opti flow +, Fisher \& Paykel Healthcare) were used. For quantitative evaluation, particle dispersion under four conditions including room air, nasal canula, and HFNC (30 or 60L/ min) were tested. Particle dispersions during rest breathing for $30 \mathrm{~s}$, speaking, and coughing were recorded three times each and automatically counted for five times each in the above conditions, and were evaluated with or without surgical masks. Dispersing droplets from mouths were flashed continuously by Parallel Eye D (Shin

\footnotetext{
*Correspondence: takahiro-takazono@nagasaki-u.ac.jp

${ }^{\dagger}$ Takahiro Takazono and Kazuko Yamamoto have Co-first author

2 Department of Infectious Diseases, Nagasaki University Graduate School

of Biomedical Sciences, 1-7-1 Sakamoto, Nagasaki 852-8501, Japan

Full list of author information is available at the end of the article
}

Nippon Air Technologies). Scattering light from droplets was recorded by a super high-sensitive camera (Eye Scope, Shin Nippon Air Technologies). The recording area was $1 \mathrm{~m}$ from participants' mouths. Particle dispersions were counted using the Fine Particle Visualization System (Type-S, Shin Nippon Air Technologies) with a $1 / 30$ s speed, which was located in two linear columns at $25-45$ and $60-80 \mathrm{~cm}$ from the mouth, respectively. Particles sized $>5 \mu \mathrm{m}$ and $>0.5 \mu \mathrm{m}$ were automatically counted independently. Differences in continuous numbers between the two groups were analyzed by ratio paired $t$ test. A $p$ value $<0.05$ was considered statistically significant.

The accumulated droplet $(>5 \mu \mathrm{m})$ dispersion in a representative participant is shown in Fig. 1, Coughing led to the maximum amount and distance of particle dispersion, regardless of modalities. Droplet dispersion was not visually increased by oxygen delivery modalities compared to room air, regardless of breathing patterns. With surgical masks over the nasal or high-flow nasal cannula, droplet dispersion was barely visible. Quantification results of particle dispersion are shown in Fig. 2. Particle dispersion counts at coughing showed a 1-log increase compared to those at speaking and more than a 2-log increase compared to those at rest breathing. Counts of droplets $(>5 \mu \mathrm{m})$ and smaller particles including aerosols $(>0.5 \mu \mathrm{m})$ were not different under nasal canula or HFNC compared to room air while speaking and coughing. Furthermore, the increased flow rate of HFNC (from $30 \mathrm{~L} /$ min to $60 \mathrm{~L} / \mathrm{min}$ ) did not affect the particle counts, even while coughing which was consistent with previous study

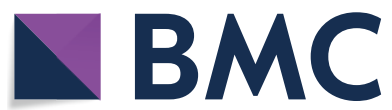

(c) The Author(s) 2021. This article is licensed under a Creative Commons Attribution 4.0 International License, which permits use, sharing, adaptation, distribution and reproduction in any medium or format, as long as you give appropriate credit to the original author(s) and the source, provide a link to the Creative Commons licence, and indicate if changes were made. The images or other third party material in this article are included in the article's Creative Commons licence, unless indicated otherwise in a credit line to the material. If material is not included in the article's Creative Commons licence and your intended use is not permitted by statutory regulation or exceeds the permitted use, you will need to obtain permission directly from the copyright holder. To view a copy of this licence, visit http://creativecommons.org/licenses/by/4.0/. The Creative Commons Public Domain Dedication waiver (http://creativecommons.org/publicdomain/zero/1.0/) applies to the data made available in this article, unless otherwise stated in a credit line to the data. 


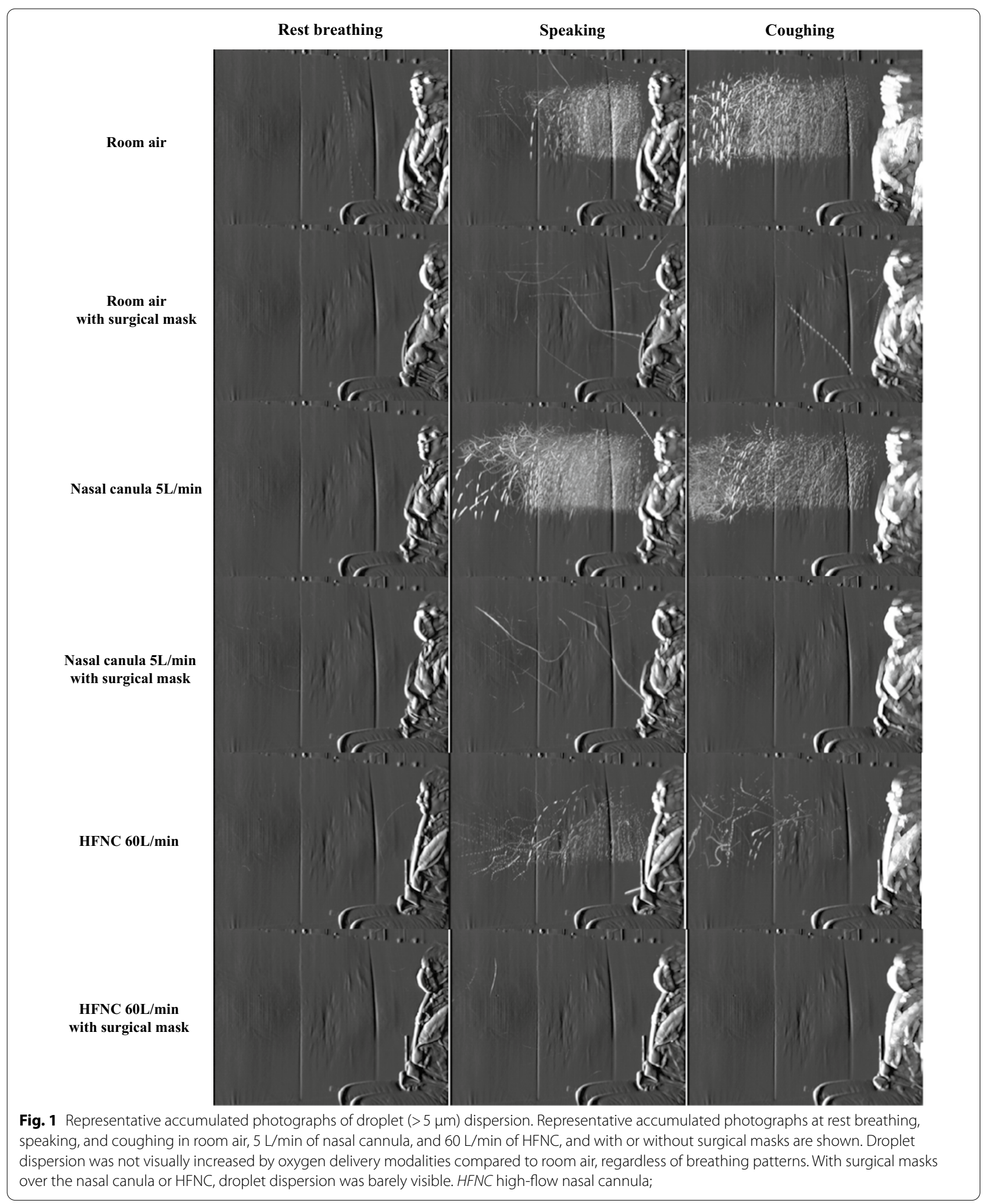




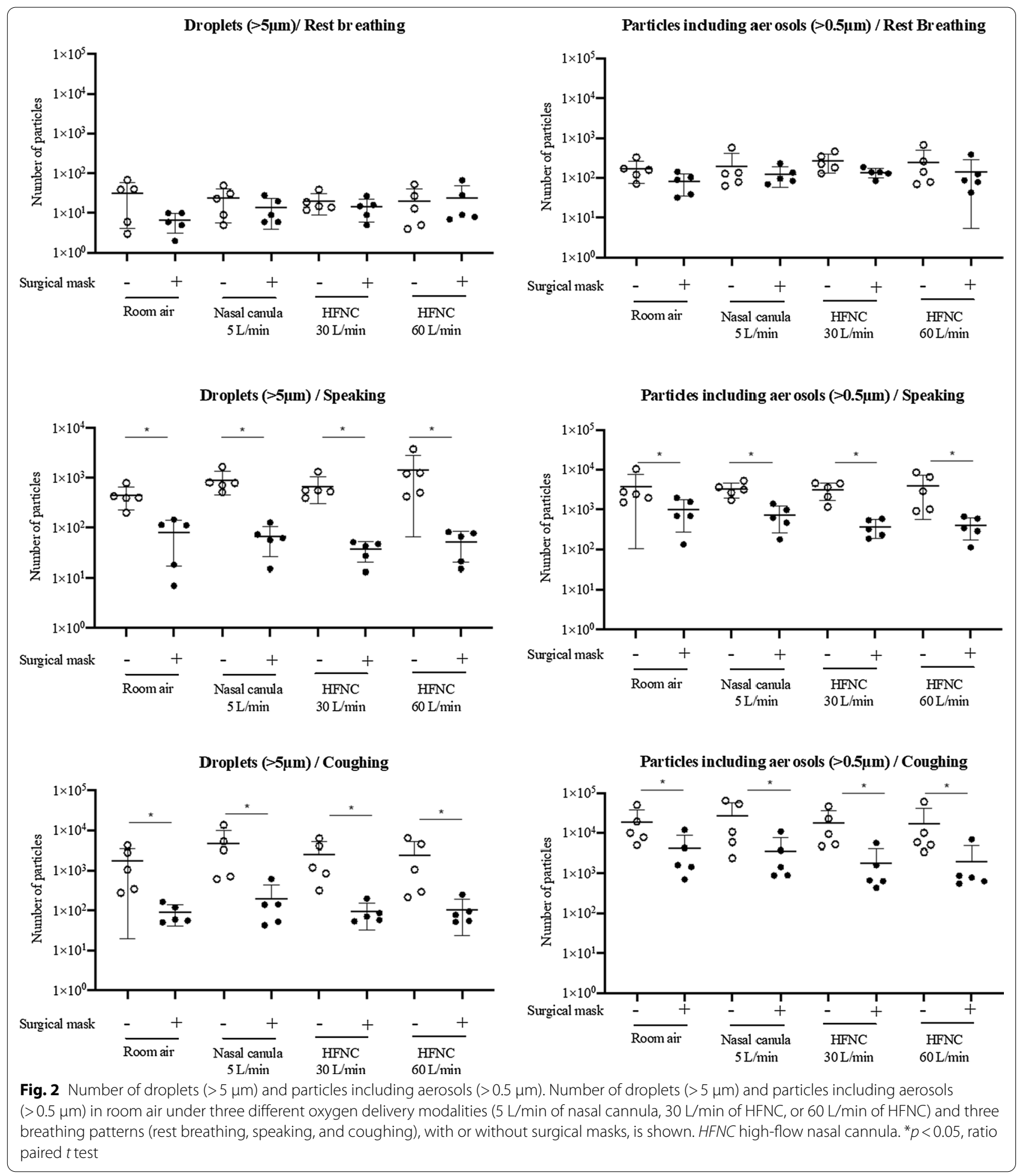

[3]. Wearing surgical masks significantly decreased particle dispersion in all modalities while speaking and coughing; reduction rates were approximately $95 \%$ and $80-90 \%$ for droplets $(>5 \mu \mathrm{m})$ and smaller particles including aerosols $(>0.5 \mu \mathrm{m})$, respectively.
The main strength of this study is that particle dispersion imaging and counts under oxygen delivery modalities, recorded by highly sensitive instruments with controlled temperature and humidity, suggested that HFNC did not generate particles. Further, the 
effectiveness of surgical mask over HFNC was promising. However, our study was assessed in healthy volunteers, and therefore, it is not certain whether these results directly apply to the patients with viral pneumonia, as those patients might not be able to wear a mask appropriately.

In conclusion, HFNC did not increase droplet and aerosol dispersion compared to standard nasal cannula therapy, even at highest flow, and surgical masks over HFNC may be safely used for acute hypoxemic respiratory failure patients, including coronavirus disease patients.

\section{Acknowledgements}

We would like to thank the technical staff at Shin Nippon Air Technologies for their supports in this study.

\section{Authors' contributions}

T.T., K.Y., R.O., and H.M performed study design. T.T., K.Y., and R.O. supervised the experiments. T.T., K.Y., K.I., and H.M interpreted the data. S.M. supervised statical analysis. T.T. and K.Y. wrote the draft, and all the authors critically reviewed the manuscript and approved the final version of the manuscript. All authors read and approved the final manuscript.

\section{Funding}

This study was supported by Fisher \& Paykel Healthcare Co, Ltd. The funding source was not involved in the study design; in the collection, analysis, or interpretation of data; in the writing of the manuscript; or in the decision to submit the manuscript for publication.

\section{Availability of data and materials}

The datasets used and/or analyzed during the current study are available from the corresponding author on reasonable request.

\section{Ethics approval and consent to participate}

This study protocol was approved by the Nagasaki University Graduate School of Biomedical Sciences Research Ethics Committee (Approval number: 20092503). Written informed consent was obtained from all the participants.

\section{Consent for publication}

Not applicable.

\section{Competing interests}

None to be declared.

\section{Author details}

${ }^{1}$ Department of Respiratory Medicine, Nagasaki University Hospital, Nagasaki, Japan. ${ }^{2}$ Department of Infectious Diseases, Nagasaki University Graduate School of Biomedical Sciences, 1-7-1 Sakamoto, Nagasaki 852-8501, Japan. 3 Infection Control and Education Center, Nagasaki University Hospital, Nagasaki, Japan. ${ }^{4}$ Visual Solution Division, Shin Nippon Air Technologies, Tokyo, Japan. ${ }^{5}$ Clinical Research Center, Nagasaki University Hospital, Nagasaki, Japan. ${ }^{6}$ Innovation Platform \& Office for Precision Medicine, Nagasaki University Graduate School of Biomedical Sciences, Nagasaki, Japan.

Received: 8 February 2021 Accepted: 17 February 2021

Published online: 27 February 2021

\section{References}

1. Elshof J, Hebbink RHJ, Duiverman ML, Hagmeijer R. High-flow nasal cannula for COVID-19 patients: risk of bio-aerosol dispersion. Eur Respir J. 2020;56(4):2003004

2. Hui DS, Chow BK, Lo T, Tsang OTY, Ko FW, Ng SS, et al. Exhaled air dispersion during high-flow nasal cannula therapy versus CPAP via different masks. Eur Respir J. 2019;53(4):1802339.

3. Gaeckle NT, Lee J, Park Y, Kreykes G, Evans MD, Hogan CJ Jr. Aerosol generation from the respiratory tract with various modes of oxygen delivery. Am J Respir Crit Care Med. 2020;202(8):1115-24.

\section{Publisher's Note}

Springer Nature remains neutral with regard to jurisdictional claims in published maps and institutional affiliations.

Ready to submit your research? Choose BMC and benefit from:

- fast, convenient online submission

- thorough peer review by experienced researchers in your field

- rapid publication on acceptance

- support for research data, including large and complex data types

- gold Open Access which fosters wider collaboration and increased citations

- maximum visibility for your research: over $100 \mathrm{M}$ website views per year

At BMC, research is always in progress.

Learn more biomedcentral.com/submissions 